\title{
Efeito de frações parcialmente purificadas de Saccharomyces cerevisiae na germinação de conídios e formação de apressórios por Colletotrichum sublineolum e Colletotrichum lagenarium ${ }^{1}$
}

\author{
Solange Maria Bonaldo ${ }^{2} \&$ Sérgio Florentino Pascholati ${ }^{3}$
}

Setor de Fitopatologia, Departamento de Entomologia, Fitopatologia e Zoologia Agrícola, Esalq/USP, Caixa Postal 9, CEP 13.418-900, Piracicaba, SP, e-mail: sfpscholesalq.usp.br

Autor para correspondência: Sérgio Florentino Pascholati

${ }^{1}$ Parte da Tese de Doutorado do primeiro autor.

${ }^{2}$ Bolsista CAPES; ${ }^{3}$ Bolsista CNPq

Data de chegada: 25/01/2005. Aceito para publicação em: 17/11/2006.

\section{RESUMO}

Bonaldo, S.M., Pascholati, S. F. Efeito de frações parcialmente purificadas de Saccharomyces cerevisiae na germinação de conídios e formação de apressórios por Colletotrichum sublineolum e Colletotrichum lagenarium. Summa Phytopathologica, v.33, n.3, p.233-238, 2007.

O trabalho teve por objetivo verificar o efeito de preparações ou de frações parcialmente purificadas obtidas de S. cerevisiae, autoclavada por 4 horas seqüencialmente, submetidas à cromatografia de troca iônica (CTI) utilizando tampão Tris- $\mathrm{HCl}$ ou bicarbonato de amônio, na germinação de esporos (GE) e formação de apressórios (FA) in vitro por C. lagenarium ou C. sublineolum. Para isto, $40 \mu \mathrm{L}$ de cada preparação ou fração foram colocados em pocinhos de placa de ELISA, juntamente com $40 \mu \mathrm{L}$ de uma suspensão de esporos $(1 \mathrm{x}$ $10^{5}$ conídios $/ \mathrm{mL}$ ) de C. lagenarium ou de C. sublineolum. Após incubação, determinou-se GE e FA. Água destilada esterilizada foi utilizada como controle. Todas as preparações da levedura autoclavada promoveram estímulo da GE, sem a formação de apressórios por ambos os fitopatógenos. Frações provenientes da CTI, com tampão Tris-HCl, induziram a GE por C. sublineolum e C. lagenarium. Na FA de C. lagenarium houve estímulo pelas frações IV, V e VI, sem diferença, no entanto, na FA de C. sublineolum. Para as frações obtidas por CTI, utilizando tampão bicarbonato de amônio, houve estímulo da GE por C. lagenarium nas frações I e IV e efeito inibitório da germinação pelas frações V, VI e VII. Não houve FA na fração I e as demais frações apresentaram efeito inibitório da FA por $C$. lagenarium. As frações I e II estimularam a GE e a FA por $C$. sublineolum e demais frações apresentaram efeito inibitório. Assim, evidencia-se a importância da escolha de tampões no processo de purificação de frações de $S$. cerevisiae, o que pode resultar em frações que estimulem a germinação de esporos de fitopatógenos fúngicos ou em frações com atividade inibitória da germinação, podendo contribuir futuramente no controle de doenças causadas por esses fungos.

Palavras-chave adicionais: cromatografia de troca iônica, levedura, fitopatógenos.

\begin{abstract}
Bonaldo, S.M., Pascholati, S. F. Effect of fractions partially purified from Saccharomyces cerevisiae on conidium germination and appressorium formation by Colletotrichum sublineolum and Colletotrichum lagenarium. Summa Phytopathologica, v.33, n.3, p.233-238, 2007.

The objective of this study was to verify the effect of preparations or fractions partially purified from S. cerevisiae, autoclavad for 4 hours sequentialy, submitted to ion-exchange chromatography (IEC), using Tris- $\mathrm{HCl}$ or ammonium bicarbonate buffers, on the in vitro conidium germination (CG) and appressorium formation (AF) of $C$. lagenarium and C. sublineolum. A total of $40 \mu \mathrm{L}$ of each preparation or fraction was placed inside the wells of ELISA plates with $40 \mu \mathrm{L}$ of a spore suspension $\left(1 \times 10^{5}\right.$ conidia/mL) of $C$. lagenarium or $C$. sublineolum. After incubation, $\mathrm{CG}$ and $\mathrm{AF}$ were determined. Distilled water was used as control. All the preparations from the autoclavad yeast stimulated $\mathrm{CG}$, without $\mathrm{AF}$ for both pathogens. Fractions from IEC, with Tris- $\mathrm{HCl}$ buffer, induced $\mathrm{CG}$ for $C$. sublineolum and $C$. lagenarium. For AF by $C$. lagenarium there was a stimulus by the

fractions IV, V and VI without difference in AF by C. sublineolum. With the fractions obtained by IEC, using ammonium bicarbonate buffer, there was a stimulation of CG by $C$. lagenarium by the fractions $\mathrm{I}$ and IV and an inhibitory effect of the germination by the fractions $\mathrm{V}, \mathrm{VI}$ and VII. There was no AF in the presence of fraction I and the other fractions exhibited inhibitory effect on AF by C. lagenarium. The fractions I and II stimulated CG and AF by C. sublineolum and other fractions presented inhibitory effect. Thus, it was showed the importance to select specific buffers during the purification of fractions of $S$. cerevisiae. This can result in fractions that stimulate $\mathrm{CG}$ and $\mathrm{AF}$ of these pathogens or in fractions with inhibitory activity on conidium germination that can contribute to control dispasps caused by these pathogens.
\end{abstract}


Saccharomyces cerevisiae Meyen é um fungo da divisão Ascomycota que produz ascos sem a produção de ascocarpos e o crescimento da colônia se dá por brotação das células, não produzindo micélio $(1,5)$. Este fungo é utilizado pelo homem na produção de bebidas alcoólicas, etanol e na panificação. Normalmente, nestes processos, a função da levedura é apenas como um agente biológico de transformação, uma vez que ao final do processo produtivo é descartada, sendo considerada como subproduto.

A levedura apresenta potencial no controle de doenças de plantas, seja por controle direto dos microrganismos fitopatogênicos, ou pela ativação de mecanismos de defesa em plantas, como as fitoalexinas. Diversos trabalhos evidenciam a capacidade da levedura $S$. cerevisiae como agente controlador de doenças em monocotiledôneas e em dicotiledôneas, contra patógenos fúngicos, virais e bacterianos (10, $11,12,13,16,17,18)$. Quando aplicada em mesocótilos de sorgo estimula a produção de fitoalexinas do tipo deoxiantocianidinas (6, 15); em cotilédones de soja promove o acúmulo de fitoalexinas do tipo gliceolina; enquanto que a aplicação em folhas de sorgo promove proteção contra patógenos fúngicos $(10,13)$. Estudos atuais se concentram na purificação e caracterização das moléculas elicitoras presentes na parede celular de $S$. cerevisiae (19). Entretanto, nos processos de purificação, o efeito das frações parcialmente purificadas tem sido somente estudado com relação à capacidade das mesmas frações em induzir os mecanismos de defesa, como as fitoalexinas, não sendo considerado o efeito que estas moléculas apresentaram sobre fitopatógenos.

Diante do exposto, o presente trabalho foi desenvolvido com o objetivo de verificar o efeito de preparações e frações obtidas da levedura S. cerevisiae na germinação de esporos e na formação de apressórios por Colletotrichum lagenarium e Colletotrichum sublineolum.

\section{MATERIAL E MÉTODOS}

\section{Obtenção das preparações de $S$. cerevisiae}

Levedura de panificação ( $S$. cerevisiae), produto comercial Fermento Biológico Fresco Fleischmann ${ }^{\circledR}$, foi utilizada como fonte de células. Utilizou-se o procedimento descrito por Roveratti (16) e a preparação resultante foi submetida a diferentes tempos de autoclavagem a $121{ }^{\circ} \mathrm{C}$ a $1 \mathrm{~atm}$, sendo dividida em dois grupos de amostras. Um grupo de amostras foi autoclavado apenas uma única vez por 10, 20,30, 40, 50 ou 60 min ou então por 1, 2, 3 ou $4 \mathrm{~h}$. Outro grupo de amostras foi obtido de uma suspensão de levedura preparada e autoclavada seqüencialmente nos tempos descritos anteriormente. Neste caso, cerca de $500 \mathrm{~mL}$ da suspensão de levedura foi preparada e aproximadamente $50 \mathrm{~mL}$ foram retirados e armazenados. A seguir, a suspensão de $S$. cerevisiae foi levada a autoclavagem, no caso da autoclavagem em minutos, esta suspensão foi autoclavada por 10 min e após este período cerca de $50 \mathrm{~mL}$ foram retirados e armazenados. A suspensão foi novamente levada a autoclavagem por mais $20 \mathrm{~min}$, e após este período cerca de 50 $\mathrm{mL}$ foram retirados e armazenados. Este procedimento foi repetido, submetendo a suspensão de levedura a mais 30, 40, 50 e 60 min de autoclavagem. Para a autoclavagem em horas, após a retirada da alíquota da suspensão não submetida a autoclavagem, a suspensão foi levada a autoclave por 1 hora e após este período cerca de 50 $\mathrm{mL}$ foram retirados e armazenados. A suspensão foi novamente levada a autoclave por mais 2,3 e $4 \mathrm{~h}$, e ao final de cada período de tempo de autoclavagem, foram coletados e armazenados aproximadamente $50 \mathrm{~mL}$ da preparação. Após a autoclavagem, as amostras foram centrifugadas a $15.000 \mathrm{~g}$ por $30 \mathrm{~min}$ a $4^{\circ} \mathrm{C}$. Os precipitados foram descartados e as preparações resultantes utilizadas no bioensaio de germinação e formação de apressórios por $C$. lagenarium e C. sublineolum.

\section{Cromatografia de troca iônica (CTI)}

A cromatografia de troca iônica foi realizada utilizando-se dois tampões para eluição do material do interior da coluna. A preparação elicitora bruta autoclavada por 4 horas seqüencialmente foi liofilizada e ressuspensa no mesmo tampão de equilíbrio da coluna.

\section{Cromatografia de troca iônica utilizando tampão Tris-HCl}

A CTI foi realizada em coluna de vidro $(2,5 \times 10 \mathrm{~cm})$ preenchida com Dietilaminoetil-Celulose (DEAE Celulose-Sigma), equilibrada com tampão Tris- $\mathrm{HCl} 10 \mathrm{mM}, \mathrm{pH} 8,0$. Uma amostra de $5 \mathrm{~mL}$ da preparação bruta dialisada em tampão de equilíbrio foi aplicada ao leito da coluna de DEAE-Celulose e eluída com o tampão de equilíbrio, a fluxo de 2,5 $\mathrm{mL} / \mathrm{min}$. Após a saída do material não adsorvido, o material adsorvido foi deslocado pelo uso de soluções de $\mathrm{NaCl}$, no tampão de equilíbrio, nas seguintes concentrações: $0,12 \mathrm{M}, 0,21 \mathrm{M}, 0,50 \mathrm{M}$ e $1 \mathrm{M}$. Foram coletadas frações de $6 \mathrm{~mL}$. As frações foram reunidas de acordo com o perfil de distribuição de proteínas e dialisadas contra água destilada (5 litros) a $4^{\circ} \mathrm{C}$, com 6 horas de intervalo entre as trocas de água (cinco repetições). As frações dialisadas, em membrana com corte para 12-14 $\mathrm{KDa}$, foram concentradas pelo uso de polietilenoglicol 20.000 e o volume final foi ajustado para $15 \mathrm{~mL}$. O conteúdo de carboidratos e de proteínas foi determinado para as frações obtidas, utilizando-se os métodos de fenol sulfúrico (4) e de Bradford (2), respectivamente. Alíquotas das frações obtidas, com dose de proteínas ajustada para a menor concentração determinada, foram avaliadas na germinação e formação de apressórios por C. lagenarium e C. sublineolum.

\section{Cromatografia de troca iônica utilizando tampão bicarbonato de amônio}

A CTI foi realizada em coluna de vidro $(2,5 \times 10 \mathrm{~cm})$ preenchida com Dietilaminoetil-Celulose (DEAE Celulose-Sigma), equilibrada com tampão bicarbonato de amônio $10 \mathrm{mM}, \mathrm{pH} 8,0$. Uma amostra de $5 \mathrm{~mL}$ da preparação bruta ressuspensa no mesmo tampão de equilíbrio da coluna foi aplicada no leito da coluna de DEAE-Celulose e eluída com o tampão de equilíbrio (bicarbonato de amônio $10 \mathrm{mM}, \mathrm{pH} \mathrm{8,0),} \mathrm{a}$ fluxo de 2,5 $\mathrm{mL} / \mathrm{min}$. Após a saída do material não adsorvido, o material adsorvido foi deslocado pelo aumento de concentração do tampão bicarbonato de amônio como segue: $0,125 \mathrm{M}, 0,25 \mathrm{M}, 0,50 \mathrm{M}$ e $1 \mathrm{M}$. Frações de $6 \mathrm{~mL}$ foram coletadas.

Nas frações coletadas a presença de proteínas foi monitorada espectrofotometricamente a $280 \mathrm{~nm}$. As frações, reunidas de acordo com o perfil de distribuição de proteínas, foram liofilizadas e ressuspensas em $10 \mathrm{~mL}$ de água destilada. O conteúdo de carboidratos e de proteínas foi novamente determinado para as frações obtidas, utilizando os métodos já citados. Alíquotas das frações obtidas, com dose de proteínas ajustada para a menor concentração determinada, foram avaliadas na germinação e formação de apressórios por $C$. lagenarium e C. sublineolum.

\section{Obtenção e manutenção dos fitopatógenos}

Colletotrichum lagenarium (Pass.) Ellis \& Halted e Colletotrichum sublineolum Henn. (sinonímia C. graminicola Ces. Wils.) foram isolados a partir de lesões em folhas de pepino e de sorgo, respectivamente, e mantidos em meio aveia-ágar, sob luz U.V., comprimento de onda longo (NUV) à temperatura de $20 \pm 2{ }^{\circ} \mathrm{C}$. 
Germinação e formação de apressórios

\section{por $C$. sublineolum e $C$. lagenarium}

Para o teste de avaliação da germinação de esporos e formação de apressórios por C. lagenarium ou C. sublineolum utilizou-se placas de teste Elisa. Portanto, uma alíquota de $40 \mu \mathrm{L}$ da suspensão de esporos e outra alíquota de $40 \mu \mathrm{L}$ dos tratamentos foram colocadas em cada um dos recipientes ("pocinhos") de uma placa usada em teste de ELISA (14). Como controle utilizou-se água destilada esterilizada sem ou com antibiótico (Pentabiótico, na concentração de $0,08 \mathrm{mg}$ / $\mathrm{mL}$ ), que foi adicionado as preparações de levedura quando estas apresentaram altas concentrações de carboidratos. Após, as placas foram incubadas sob luz constante a $25 \pm 2{ }^{\circ} \mathrm{C}$. A porcentagem de germinação e formação de apressórios foi determinada 24 horas após o início do experimento, através do emprego de $20 \mu \mathrm{L}$ do corante azul algodão de lactofenol, utilizado para paralisar a germinação. A avaliação foi realizada através da observação ao microscópio ótico com aumento de 400 vezes. Contou-se 100 esporos por repetição, totalizando 800 esporos por tratamento. Foram considerados como esporos germinados aqueles que apresentaram qualquer indício de emissão do tubo germinativo.

\section{RESULTADOS E DISCUSSÃO}

\section{Separação dos compostos por cromatografia de troca iônica}

O resultado da CTI com tampão Tris-HCl é apresentado na Figura 1a. De acordo com o perfil de proteínas das frações obtidas estas
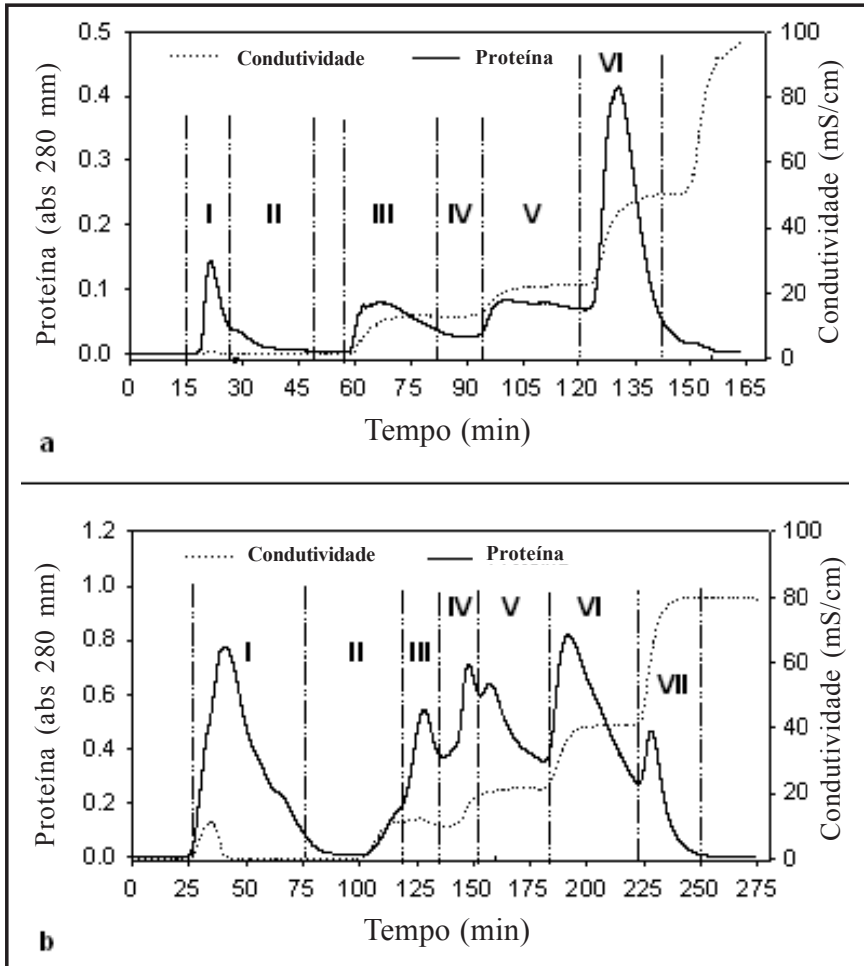

Figura 1. Cromatografia de troca iônica da preparação de Saccharomyces cerevisiae autoclavada 4 horas seqüencialmente, em coluna empacotada com a resina DEAE-Celulose. (a) Coluna equilibrada e eluída com tampão Tris- $\mathrm{HCl}$ 0,01 M (pH 8,0), e eluição do material adsorvido à resina através de soluções de $\mathrm{NaCl}$ a $0,12 \mathrm{M}, 021 \mathrm{M}, 0,50 \mathrm{M}$ e $1 \mathrm{M}$. As frações coletadas foram reagrupadas, conforme o perfil de proteínas para formação de seis novas frações: I, II, III, IV, V e VI. (b) Coluna equilibrada e eluída com tampão bicarbonato de amônio 0,01 M (pH 8,0), e eluição do material adsorvido com o próprio tampão a $0,125 \mathrm{M}, 0,25 \mathrm{M}, 0,50 \mathrm{M}$ e $1 \mathrm{M}$. As frações coletadas foram reagrupadas, conforme o perfil de proteínas para formação de sete novas frações: I, II, III, IV, V, VI e VII. foram agrupadas formando seis frações. A dosagem de carboidratos das frações agrupadas mostrou alta concentração na fração I, seguida pela fração III (Tabela 1). Com relação às proteínas, as frações III e V apresentaram as maiores concentrações e a fração II o menor conteúdo de proteínas. Resultados das CTI com tampão bicarbonato de amônio são apresentados na Figura 1b. Foram obtidas sete frações após o reagrupamento de acordo com o perfil de proteínas. A fração I apresentou alta concentração de carboidratos seguida pela fração III (Tabela 1). Com relação ao conteúdo de proteínas a fração $\mathrm{V}$ apresentou a maior concentração e a fração VII a menor.

Tabela 1. Concentração de proteínas e carboidratos das frações parcialmente purificadas, obtidas de Saccharomyces cerevisiae autoclavada por 4 horas seqüencialmente, através de cromatografia de troca iônica (CTI)

\begin{tabular}{lll}
\hline Frações & $\begin{array}{l}\text { Proteínas } \\
(\mu \mathrm{g} / \mathrm{mL})^{*}\end{array}$ & $\begin{array}{l}\text { Carboidratos } \\
(\mu \mathrm{g} / \mathrm{mL})^{*}\end{array}$ \\
\hline
\end{tabular}

CTI com tampão Tris-HCl

$\begin{array}{lll}\text { Fração I } & 388,28 \pm 35,43 & 13.737,24 \pm 3.411,48 \\ \text { Fração II } & 246,34 \pm 25,53 & 206,63 \pm 12,03 \\ \text { Fração III } & 692,31 \pm 9,52 & 3.418,37 \pm 210,11 \\ \text { Fração IV } & 500,00 \pm 12,59 & 545,92 \pm 21,74 \\ \text { Fração V } & 618,13 \pm 19,81 & 129,34 \pm 38,52 \\ \text { Fração VI } & 427,66 \pm 35,00 & 150,51 \pm 9,88\end{array}$

$\begin{array}{lcl}\text { CTI com tampão bicarbonato de amônio } & \\ \text { Fração I } & 948,72 \pm 27,52 & 50.306,12 \pm 1.079,80 \\ \text { Fração II } & 718,86 \pm 71,24 & 5.136,00 \pm 1.961,00 \\ \text { Fração III } & 824,18 \pm 24,72 & 10.000,00 \pm 2.959,20 \\ \text { Fração IV } & 912,09 \pm 59,88 & 1.734,60 \pm 3.270,00 \\ \text { Fração V } & 1.053,11 \pm 2,66 & 322,60 \pm 8,60 \\ \text { Fração VI } & 809,52 \pm 33,57 & 172,00 \pm 19,80 \\ \text { Fração VII } & 391,94 \pm 20,25 & 1.226,20 \pm 147,60\end{array}$

Média de três repetições seguida pelo desvio padrão.

Nos bioensaios de germinação e formação de apressórios por $C$. lagenarium e C. sublineolum as frações obtidas tiveram a concentração de proteínas ajustada de acordo com a menor concentração de proteínas das frações. Frações obtidas na primeira CTI foram ajustadas de acordo com a concentração de proteínas da fração II $(246,34 \mu \mathrm{g} / \mathrm{mL})$; e concentrações de proteínas das frações obtidas na segunda CTI foram igualadas a concentração de proteínas da fração VII $(391,94 \mu \mathrm{g} / \mathrm{mL})$. Extrato bruto (levedura autoclavada por 4 horas seqüencialmente) foi utilizado nos bioensaios com a concentração original de proteínas $(1.135 \mu \mathrm{g} / \mathrm{mL})$ e de carboidratos $(40.340 \mu \mathrm{g} / \mathrm{mL})$.

Efeito de preparações de $S$. cerevisiae na germinação e formação de apressórios por $C$. sublineolum e $C$. lagenarium

Todas as preparações de $S$. cerevisiae autoclavadas uma vez ou seqüencialmente, por min ou h, induziram a germinação de esporos de C. lagenarium e C. sublineolum, sem a formação de apressórios (dados não mostrados). Esse efeito na germinação de esporos por fitopatógenos pode ser estar relacionado à presença de substâncias estimuladoras nas preparações de levedura ou por estas apresentarem nutrientes em qualidade e concentrações favoráveis aos fitopatógenos. Por exemplo, a presença de nutrientes prontamente disponíveis, em concentrações adequadas, inativa a micosporina-alanina, um 
autoinibidor de germinação encontrado na mucilagem que envolve os conídios de C. sublineloum (9).

\section{Efeito de frações parcialmente purificadas obtidas de $S$. cerevisiae na germinação e formação de apressórios por $C$. sublineolum e $C$. lagenarium}

Todas as frações obtidas após CTI com tampão Tris-HCl, induziram a germinação de esporos por C. lagenarium (Figura 2) e houve efeito estimulador na formação de apressórios pelo fungo nas frações IV, V e VI. Por sua vez, na germinação de C. sublineolum somente a fração I não promoveu estímulo da germinação não diferindo do controle (água) (Figura 3). Não houve efeito das frações testadas na formação de apressórios, enquanto que o extrato bruto favoreceu a germinação de esporos, mas sem formação de apressórios por $C$. sublineolum. Ausência da formação de apressórios em patógenos como C. lagenarium e C. sublineolum, pode auxiliar no controle da doença provocada por estes fitopatógenos, pois o apressório é uma estrutura de infecção especializada que se forma a partir de uma hifa ou tubo germinativo, o qual é importante no processo de penetração do fungo através da superfície foliar do hospedeiro (7).

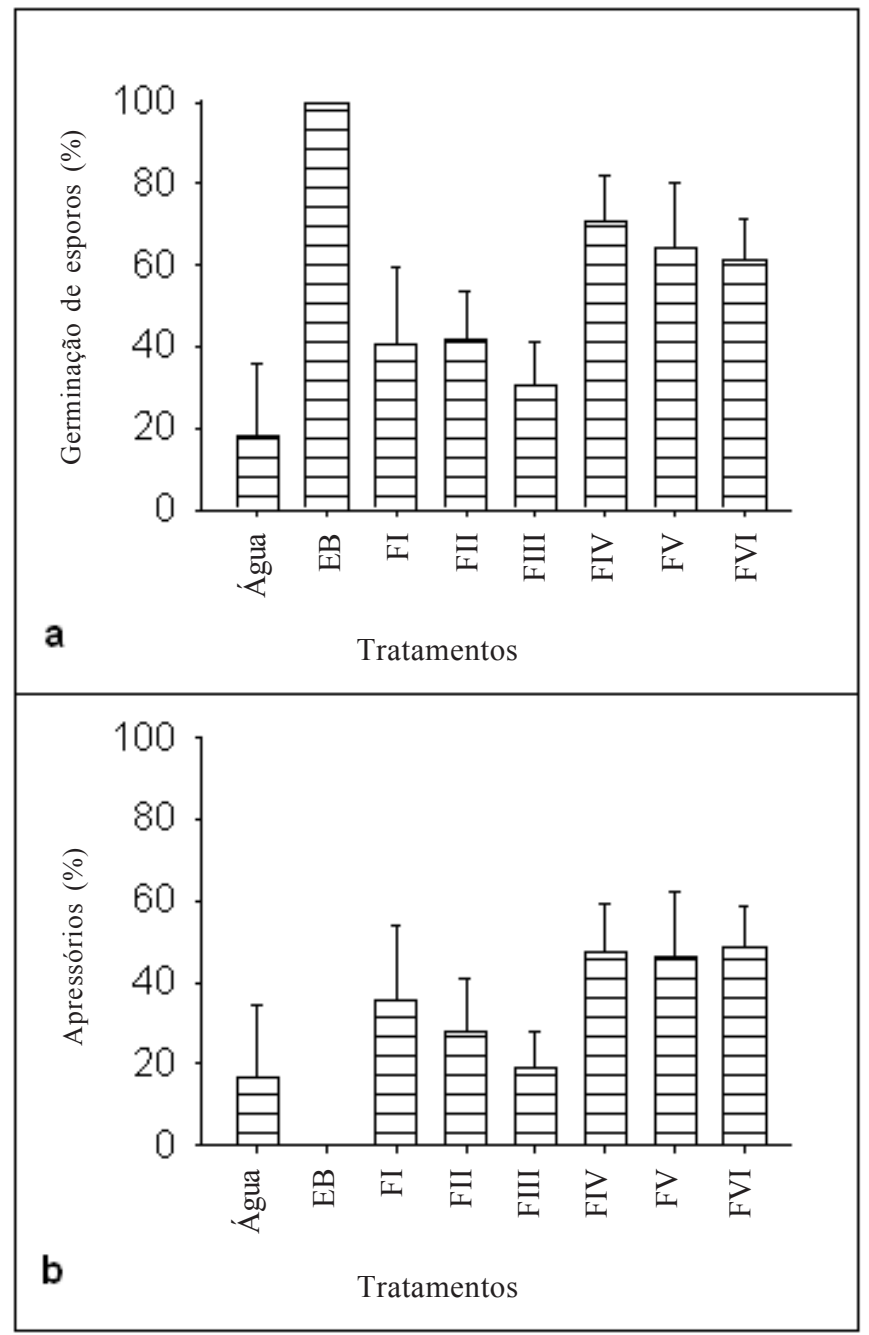

Figura 2. Efeito das frações provenientes da cromatografia de troca iônica com tampão Tris- $\mathrm{HCl}$ na germinação e formação de apressórios por Colletotrichum lagenarium. (a) Germinação de esporos. (b) Formação de apressórios. Suspensão de esporos do patógeno: 1 x $10^{5}$ conídios $/ \mathrm{mL}$. EB: extrato bruto. As barras representam o desvio padrão da média de oito repetições.

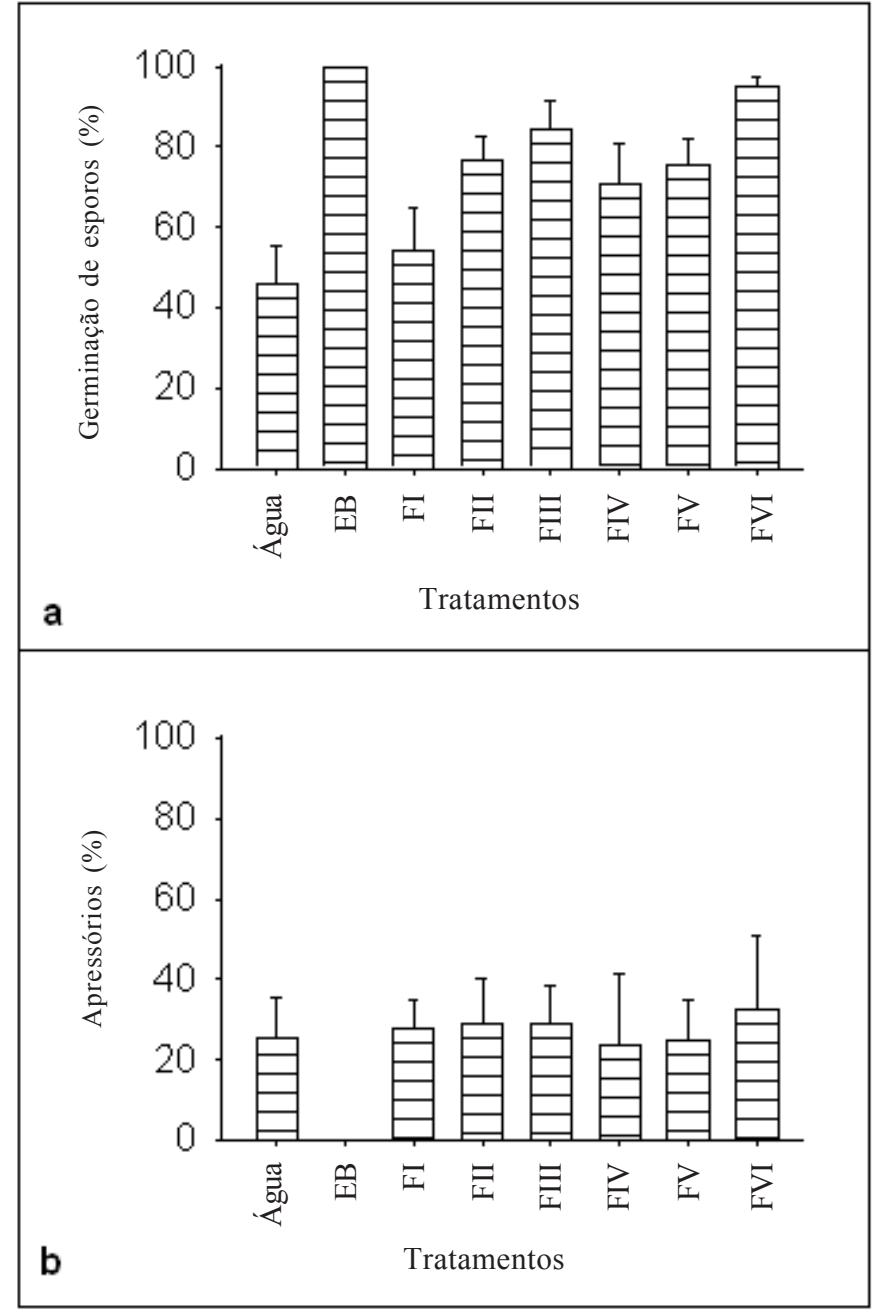

Figura 3. Efeito das frações provenientes da cromatografia de troca iônica com tampão Tris- $\mathrm{HCl}$ na germinação e formação de apressórios por Colletotrichum sublineolum. (a) Germinação de esporos. (b) Formação de apressórios. Suspensão de esporos do patógeno: 1 x $10^{5}$ conídios/mL. EB: extrato bruto. As barras representam o desvio padrão da média de oito repetições.

No teste com as frações obtidas por CTI, utilizando tampão bicarbonato de amônio, houve estímulo da germinação de $C$. lagenarium nas frações I e IV. Provavelmente, nestas frações estejam presentes os compostos (moléculas) estimuladores presentes no extrato bruto e que foram separados das frações com atividade inibitória por CTI com tampão bicarbonato de amônio. Houve inibição da germinação pelas frações V, VI e VII e as outras frações não apresentaram efeito estatisticamente significativo em relação ao controle (água) (Figura 4). Não houve formação de apressórios por C. lagenarium na fração I e todas as outras frações testadas reduziram a formação de apressórios. Para C. sublineolum (Figura 5), as frações I e II estimularam a germinação de esporos e a formação de apressórios e as frações III, IV, V, VI e VII apresentaram efeito inibitório na germinação e formação de apressórios. Houve efeito estimulador do extrato bruto na germinação de $C$. lagenarium e de $C$. sublineolum, sem a formação de apressórios (Figuras 4 e 5).

A germinação de esporos é um estágio do desenvolvimento no ciclo de todos os fungos filamentosos, sendo necessário à presença de nutrientes com baixo peso molecular (aminoácidos 


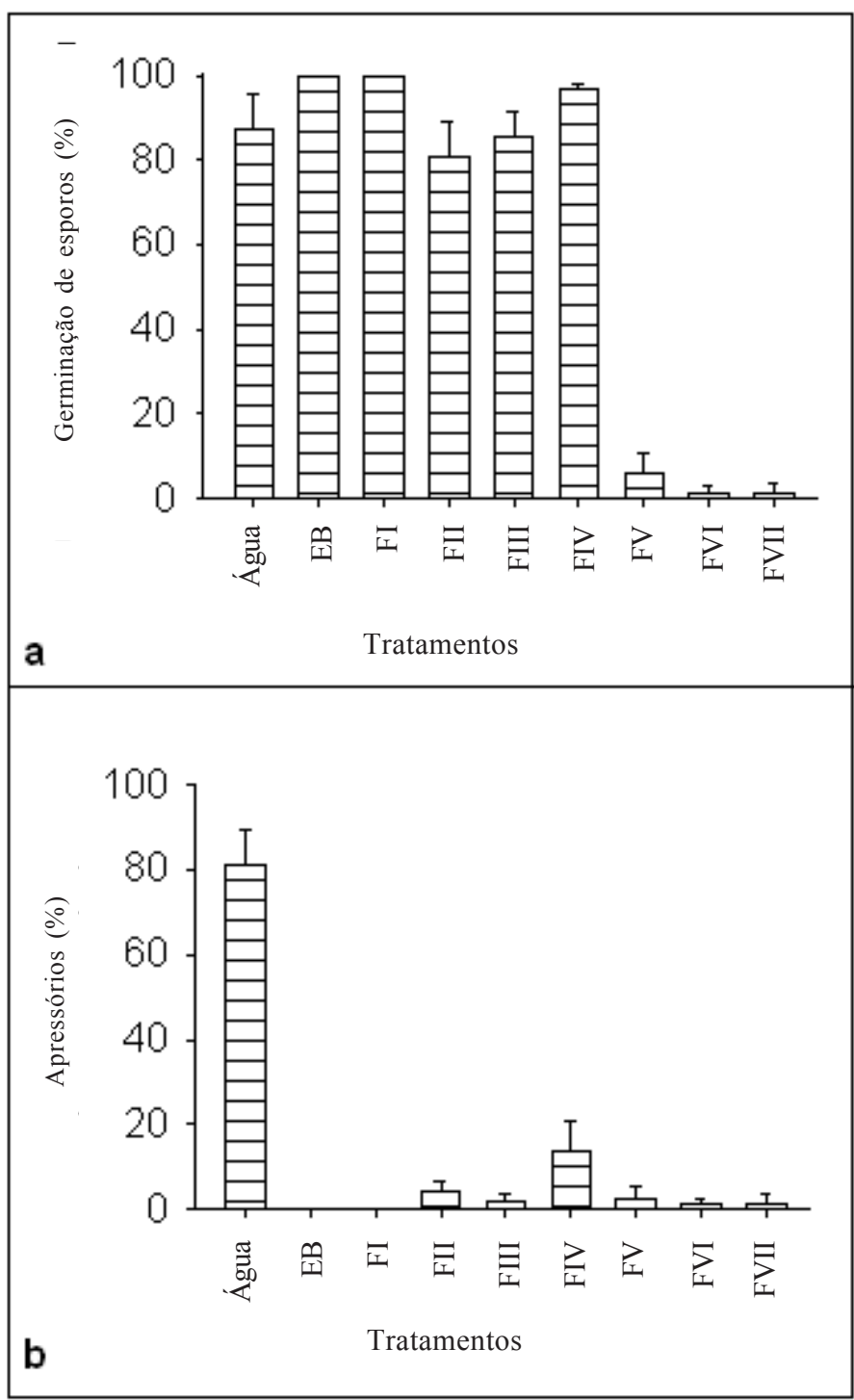

Figura 4. Efeito das frações provenientes da cromatografia de troca iônica com tampão bicarbonato de amônio na germinação e formação de apressórios por Colletotrichum lagenarium. (a) Germinação de esporos. (b) Formação de apressórios. Suspensão de esporos do patógeno: $1 \times 10^{5}$ conídios/mL. EB: extrato bruto. As barras representam o desvio padrão da média de oito repetições.

e açúcares) para que a mesma ocorra (3). Portanto, o efeito estimulador da germinação de esporos pelas frações e pelo extrato bruto, provavelmente está relacionado à disponibilidade de nutrientes. Labanca (8) trabalhando com $S$. cerevisiae relatou a obtenção de frações sem efeito no crescimento micelial de $C$. lagenarium, com estímulo da esporulação pelo fitopatógeno.

Como observado neste trabalho, as frações provenientes da CTI com tampão bicarbonato podem apresentar efeito inibidor ou não para diferentes estruturas dos fitopatógenos. Portanto, estudos futuros devem ser realizados para avaliar a natureza das frações com atividade inibitória, onde o emprego de proteinase $\mathrm{k}$ e/ou metaperiodato de sódio, por exemplo, podem colaborar para a elucidação da natureza da (s) molécula (s) com atividade fungitóxica e futuramente contribuir para a obtenção de moléculas/produtos com potencial no controle das doenças causadas por esses fungos fitopatogênicos.

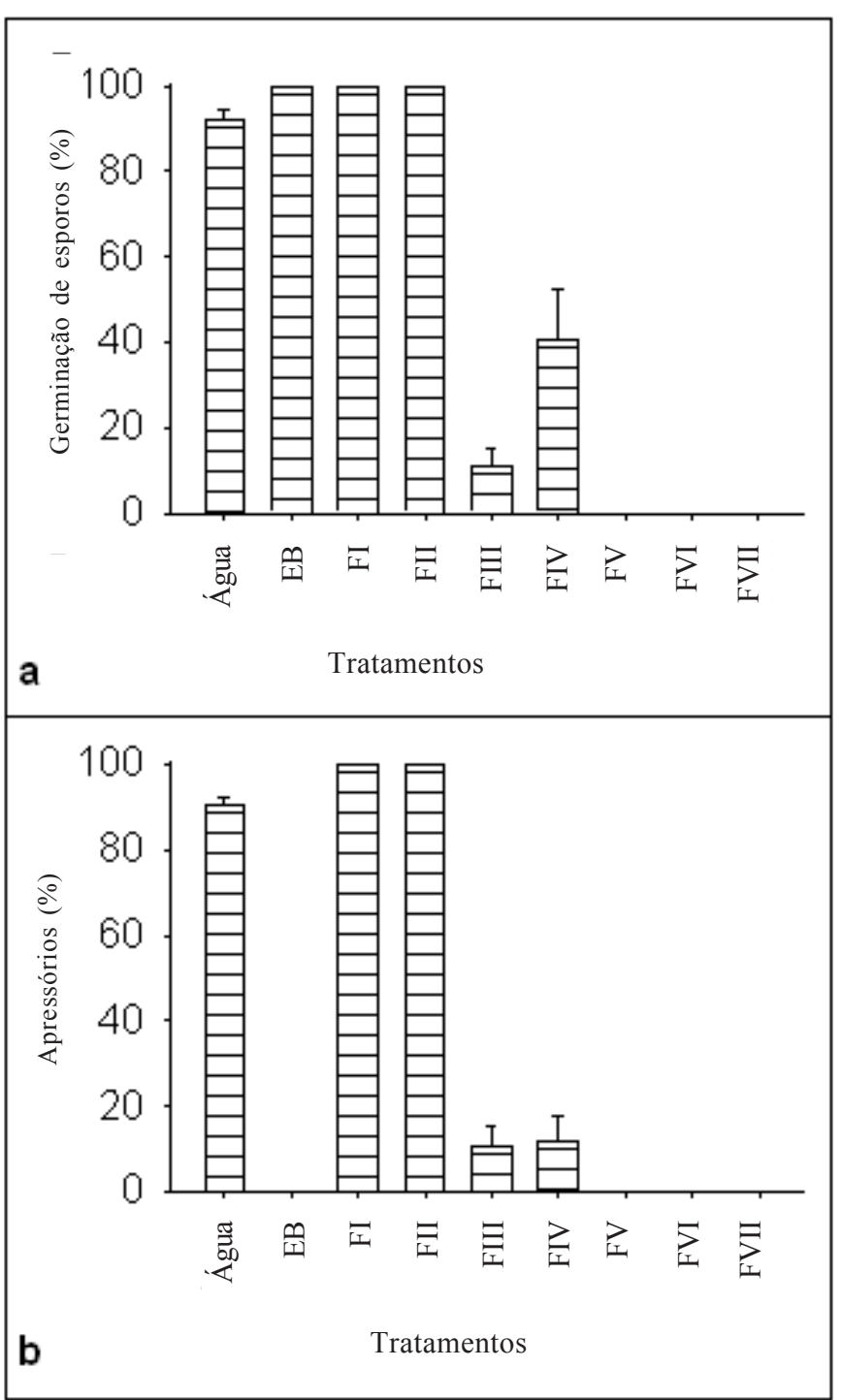

Figura 5. Efeito das frações provenientes da cromatografia de troca iônica com tampão bicarbonato de amônio na germinação e formação de apressórios por Colletotrichum sublineolum. (a) Germinação de esporos. (b) Formação de apressórios. Suspensão de esporos do patógeno: 1 x $10^{5}$ conídios/mL. EB: extrato bruto. As barras representam o desvio padrão da média de oito repetições.

\section{REFERÊNCIAS BIBLIOGRÁFICAS}

1. Agrios, G.N. Plant pathology. 4. ed. San Diego: Academic Press, 1997. 635p.

2. Bradford, M.A. A rapid and sensitive method for the quantitation of microgram quanties of protein utilizing the principle of protein-dye binding. Analytical Biochemistry, San Diego, v.72, n.1/2, p.248-254, 1976.

3. D'Enfert, C. Fungal spore germination: insights from the molecular genetics of Aspergillus nidulans and Neurospora cras$s a$. Fungal Genetics and Biology, San Diego, v.21, n.2, p.163-172, 1997.

4. Dubois, M.; Haminton, K.; Rebers, P.; Smith, C. Colorimetric methods for determination of sugar and related substances. Analytical Chemistry, Washington, v.28, n.3, p.350-356, 1956 .

5. Isaac, S. Fungal and plant interactions. London: Chapman and Hall, 1992. 418p. 
6. Freitas, J.C.; Zaramella, G.S.; Pascholati, S.F. Efeito de agentes bióticos e abióticos no acúmulo de um complexo de pigmentos e fitoalexinas em mesocótilos de sorgo. Fitopatologia Brasileira, Brasília, v.18, supl., p.349, 1993. (Resumo).

7. Khan, A.; Hsiang, T. The infection process of Colletotrichum graminicola and relative aggressiveness on four turfgrass species. Canadian Journal of Microbiology, Ottawa, v.49, p.433-442, 2003.

8. Labanca, E.R.G. Purificação parcial de elicitores presentes em Saccharomyces cerevisiae: atividade como indutores de resistência em pepino (Cucumis sativus) contra Colletotrichum lagenarium e da síntese de gliceolinas em soja (Glycine max). 2002. 118p. Dissertação (Mestrado em Agronomia) Escola Superior de Agricultura "Luiz de Queiroz", Universidade de São Paulo, Piracicaba.

9. Leite, B.; Nicholson, R.L. Mycosporine-alanine: a self-inhibitor of germination from the conidial mucilage of Colletotrichum graminicola. Experimental Mycology, San Diego, v.16, n.1, p.76-86, 1992.

10. Lopez, A.M.Q. Controle alternativo de antracnose causada por Colletotrichum graminicola (Ces) Wills em sorgo (Sorghum bicolor L. (Moench)). 1991. 203p. Dissertação (Mestrado em Biologia) - Instituto de Biociências, Universidade Estadual Paulista, Rio Claro.

11. Pascholati, S.F. Potencial de Saccharomyces cerevisiae e outros agentes bióticos na proteção de plantas contra patógenos. 1998. Tese (Livre Docência em Fitopatologia). Escola Superior de Agricultura "Luiz de Queiroz", USP, Piracicaba.

12. Piccinin, E.; Di Piero, R.M.; Pascholati, S.F. Efeito de Saccharomyces cerevisiae na produtividade de sorgo e na severidade de doenças foliares em campo. Fitopatologia Brasileira, Brasília, v.30, n.1, p.5-9, 2005.
13. Piccinin, E. Uso de Saccharomyces cerevisiae na proteção de plantas de sorgo (Sorghum bicolor), maracujá azedo (Passiflora edulis) e eucalipto (Eucaliptus spp.) contra fitopatógenos fúngicos e bacterianos. 1995. 107p. Dissertação (Mestrado em Agronomia) - Escola Superior de Agricultura "Luiz de Queiroz", Universidade de São Paulo, Piracicaba.

14. Regente, M.C.; Oliva, C.R.; Ffeldman, M.L.; Castagnaro, A.P.; Canal, L. A sunflower leaf antifungal peptide active against Sclerotinia sclerotiorum. Physiologia Plantarum, Kobenhavn, v.100, n.1, p.178-182, 1997.

15. Roncatto, M. C.; Pacholati, S. F. Mesocótilos estiolados de sorgo: bioensaio para a caracterização de frações de Saccharomyces cerevisiae envolvidas na proteção de plantas de sorgo contra fungos. In: Reunião Anual do Instituto Biológico, 6, 1993, São Paulo. Resumos. São Paulo: Instituto Biológico, 1993. p.31.

16. Roveratti, D.S. Proteção de plantas de café (Coffea arabica L.) contra Hemileia vastatrix Berk. et Br. por Saccharomyces cerevisiae. 1989. 94p. Dissertação (Mestrado em Agronomia) Escola Superior de Agricultura "Luiz de Queiroz", Universidade de São Paulo, Piracicaba.

17. Silva, S.R.; Pascholati, S.F. Saccharomyces cerevisiae protects maize plants, under greenhouse conditions, against Colletotrichum graminicola. Journal of Plant Disease and Protection, Stuttgart, v.99, n.2, p.159-167, 1992.

18. Stangarlin, J.R.; Pascholati, S.F. Proteção de plântulas de milho pipoca contra Exserohilum turcicum pelo uso de Saccharomyces cerevisiae. Summa Phytopathologica, Jaguariúna, v.20, n.1, p.16-21, 1994

19. Wulff, N.A.; Pascholati, S.F. Caracterização parcial de elicitores de fitoalexinas em sorgo isolados de Saccharomyces cerevisiae. Fitopatologia Brasileira, Brasília, v.24, n.3, p.428-435, 1999. 